\title{
EXTRAÇÃO DE SILÍCIO EM SOLOS FERTILIZADOS COM FOSFATO E SILICATO ${ }^{1}$
}

\author{
Robson Santos Gutierrez², Maykom Ferreira Inocêncio ${ }^{3}$, José Oscar Novelino²
}

\begin{abstract}
EXTRACTION OF SILICON IN SOILS

FERTILIZED WITH PHOSPHATE AND SILICATE

The objective of this study was to evaluate the levels of silicon ( $\mathrm{Si}$ ) extracted by using calcium chloride and acetic acid solutions, in Haplortox soil samples fertilized with phosphate and silicate. The experimental design was completely randomized, in a $5 \times 2$ factorial scheme, consisting of five doses of phosphorus (P) $\left(0 \mathrm{mg} \mathrm{dm}^{-3}, 96 \mathrm{mg} \mathrm{dm}^{-3}, 192 \mathrm{mg} \mathrm{dm}^{-3}, 288 \mathrm{mg} \mathrm{dm}^{-3}\right.$, and $\left.480 \mathrm{mg} \mathrm{dm}^{-3}\right)$, in the absence and presence of $300 \mathrm{mg} \mathrm{dm}^{-3}$ of $\mathrm{Si}$. The experimental units were submitted to two incubation periods, the first with silicate (half of the portions) and the second with limestone (remaining of the portions). After incubation, the soil samples received the $\mathrm{P}$ doses and were cultivated with corn plants. The Si level in the soil, measured by using extracting solutions, and the $\mathrm{Si}$ and $\mathrm{P}$ contents in the dry matter of the aerial part were evaluated. Significant effect was observed for $\mathrm{Si}$, phosphate levels, and for the interaction Si x phosphate doses, in relation to the Si content extracted from the soil. The acetic acid solution extracted more $\mathrm{Si}$ than the calcium chloride solution, independently of the slag fertilization.
\end{abstract}

KEY-WORDS: Zea mays L.; slag; phosphorus; extractors.

\section{INTRODUÇÃO}

A maioria dos solos brasileiros encontra-se em estágio avançado de intemperismo, apresentando elevada acidez, baixa disponibilidade de nutrientes e argilas de baixa atividade, que resultam em baixa capacidade de troca de cátions (CTC) (Casagrande et al. 2003). Estas características favorecem o desenvolvimento de cargas positivas no colóide, as quais formam compostos de alta energia de ligação com o fósforo (P) (Souza et al. 2002). Por este motivo, o P é o nutriente com maior potencial para limitar a produtividade agrícola destes solos.

\section{RESUMO}

O objetivo deste estudo foi avaliar os teores de silício (Si) extraídos por soluções de cloreto de cálcio ou ácido acético, em amostras de Latossolo Vermelho distroférrico, fertilizadas com fosfato e silicato. O delineamento experimental foi inteiramente casualizado, em esquema fatorial $5 \times 2$, constituído pela combinação de cinco doses de fósforo (P) (0 mg dm${ }^{-3}, 96 \mathrm{mg} \mathrm{dm}^{-3}, 192 \mathrm{mg} \mathrm{dm}^{-3}, 288 \mathrm{mg} \mathrm{dm}^{-3}$ e $480 \mathrm{mg} \mathrm{dm}^{-3}$ ), na ausência e presença de $300 \mathrm{mg} \mathrm{dm}^{-3} \mathrm{de} \mathrm{Si}$. As unidades experimentais foram submetidas a dois períodos de incubação, o primeiro com escória (metade das parcelas) e o segundo com calcário dolomítico (restante das parcelas). Após a incubação, as amostras de solo receberam as doses de $\mathrm{P}$ e foram cultivadas com plantas de milho. Foram avaliados os teores de Si no solo, extraídos pelas soluções extratoras, e os conteúdos de Si e P, na matéria seca da parte aérea. Observou-se efeito significativo para o $\mathrm{Si}$, doses de fosfato e para a interação Si x doses de fosfato, quanto aos teores de Si extraídos do solo. A solução de ácido acético extraiu mais Si do que a solução de cloreto de cálcio, independentemente da fertilização com escória.

PALAVRAS-CHAVE: Zea mays L.; Escória de siderurgia; fósforo; extratores.

Vários são os atributos do solo que podem influenciar na adsorção de fósforo, sendo os principais o tipo e teor de argila, de colóides amorfos e de matéria orgânica (Novais \& Smyth 1999). Quanto mais intemperizado o solo, maior tende a ser sua capacidade de fixação de $\mathrm{P}$, o que justifica a necessidade de doses elevadas do nutriente, nos solos altamente intemperizados do Cerrado.

Como o P se encontra no solo na forma aniônica de $\mathrm{H}_{2} \mathrm{PO}_{4}^{-}$e $\mathrm{HPO}_{4}^{-}$, uma alternativa que vem sendo estudada para reduzir a adsorção do nutriente às cargas positivas dos colóides é a competição de outros ânions, como o silicato, com o P, pelos sítios da fase sólida do solo (Ma et al. 2001).

1. Trabalho recebido em dez./2009 e aceito para publicação em jan./2011 (nº registro: PAT 8316/ DOI 10.5216/pat.v41i1.8316).

2. Universidade Federal da Grande Dourados, Faculdade de Ciências Agrárias, Departamento de Solos, Dourados, MS, Brasil.

E-mails: agrogrilo@hotmail.com,jnovel@ufgd.com.

3. Universidade Federal de Lavras, Escola de Agronomia, Departamento de Ciência do Solo, Lavras, MG, Brasil.

E-mail: maykomagronomia@yahoo.com.br. 
O Si representa cerca de $27 \%$ da massa da crosta terrestre e é importante na formação dos solos (Tisdale et al. 1985). No entanto, os solos tropicais e subtropicais, principalmente os oxídicos, tendem a apresentar baixos teores de Si trocável na solução do solo, podendo ser de 5 a 10 vezes menores que os encontrados nas regiões temperadas (Otsubo \& Coutinho 2001). A adequada nutrição das plantas com Si tem sido associada ao aumento da resistência ao ataque de patógenos e da produtividade e qualidade dos produtos agrícolas, principalmente em espécies acumuladoras do nutriente, como o arroz, o sorgo e o milho, dentre outras (Lima Filho et al. 1999).

Apesar da importância do nutriente para a nutrição de plantas, a análise de Si no solo não é rotina em laboratórios no Brasil, o que pode ser atribuído, dentre outros fatores, à falta de correlação dos métodos para $\mathrm{Si}$, e tem dificultado, também, o desenvolvimento de pesquisas relacionadas ao nutriente (Camargo et al. 2005).

Atualmente, os métodos empregados para avaliar a disponibilidade de $\mathrm{Si}$ às plantas utilizam soluções extratoras, como o ácido acético $0,5 \mathrm{~mol} \mathrm{~L}^{-1}$ (Snyder 2001) e o $\mathrm{CaCl}_{2}$ 0,01 $\mathrm{mol} \mathrm{L}^{-1}$ (Berthelsen et al. 2002). As soluções mais eficientes são as ácidas, em comparação às soluções neutras. No entanto, em algumas situações, os extratores ácidos resultam na superestimativa dos teores de Si solúvel (Sumida 2002), o que tem sido relacionado, dentre outros fatores, ao pH da solução extratora.

Neste contexto, objetivou-se, com este trabalho, avaliar a eficiência de extratores de $\mathrm{Si}$, em solo fertilizado com escória de siderurgia e fosfato, e a acumulação destes nutrientes em plantas de milho cultivado na época da "safrinha".

\section{MATERIAL E MÉTODOS}

O experimento foi realizado em casa-de-vegetação da Faculdade de Ciências Agrárias da Universidade Federal da Grande Dourados (UFGD) (22 $2^{\circ} 13^{\prime} 16^{\prime \prime} \mathrm{S}, 54^{\circ} 17^{\prime} 01^{\prime \prime} \mathrm{W}$ e altitude de $430 \mathrm{~m}$ ), em
Dourados (MS). O milho foi cultivado em vasos com capacidade para 4,5 L, de 11/05/2007 a 25/06/2007. O delineamento experimental utilizado foi o inteiramente casualizado, em esquema fatorial $5 \times 2$, constituído pela combinação de cinco níveis de $\mathrm{P}$ $\left(0 \mathrm{mg} \mathrm{dm}^{-3}, 96 \mathrm{mg} \mathrm{dm}^{-3}, 192 \mathrm{mg} \mathrm{dm}^{-3}, 288 \mathrm{mg} \mathrm{dm}^{-3} \mathrm{e}\right.$ $480 \mathrm{mg} \mathrm{dm}^{-3}$ ), na ausência e presença de $300 \mathrm{mg} \mathrm{dm}^{-3}$ de $\mathrm{Si}$, com quatro repetições.

Cada unidade experimental foi representada por um vaso, preenchido com $3,6 \mathrm{dm}^{3}$ de terra fina seca ao ar, retirada da camada 0-0,2 m de um Latossolo Vermelho distroférrico (LVdf) de textura muito argilosa. A caracterização química e física do solo é apresentada nas Tabelas 1 e 2.

Os níveis de $\mathrm{P}$ foram estimados a partir do valor de $\mathrm{P}$ remanescente, segundo procedimentos descritos em Alvarez et al. (2000). A fonte de P foi o fosfato biácido de sódico, reagente analítico com percentagem de $\mathrm{P}$ de $26 \%$ e de $\mathrm{P}_{2} \mathrm{O}_{5}$ de $60 \%$, e o silicato foi fornecido pela aplicação de escória de siderurgia, contendo 78,1 $\mathrm{g} \mathrm{kg}^{-1}$ de Si ou $167,3 \mathrm{~g} \mathrm{~kg}^{-1}$ de $\mathrm{SiO}_{2}$. A análise de $\mathrm{Si}$ total na escória foi realizada a partir do ataque com ácido fluorídrico mais ácido clorídrico concentrado, segundo metodologia descrita em Korndörfer et al. (2004).

Os tratamentos com a escória de siderurgia, na dose de $300 \mathrm{mg} \mathrm{dm}^{-3}$ de $\mathrm{Si}$, foram aplicados em 20 unidades experimentais, sendo outras 20 unidades experimentais sem escória também preparadas. Após as homogeneizações, todas as unidades experimentais foram incubadas em laboratório, durante 20 dias, em sacos plásticos, com teor de água destilada corrigido de modo a ocupar $60 \%$ do volume total de poros, determinado conforme Tedesco et al. (1985).

Após o período de incubação, as amostras de solo foram submetidas a análises de Cálcio (Ca) e Magnésio $(\mathrm{Mg})$ trocáveis e, nas unidades experimentais que não receberam escória de siderurgia, o equilíbrio destes cátions foi estabelecido com o uso de carbonatos de $\mathrm{Ca}\left(\mathrm{CaCO}_{3}\right)$ e $\mathrm{Mg}\left(\mathrm{MgCO}_{3}\right)$, na relação 4:1 (cálcio:magnésio). Após a aplicação dos corretivos, as unidades experimentais permaneceram

Tabela 1. Caracterização química do Latossolo Vermelho distroférrico utilizado no experimento (Dourados, MS, 2007).

\begin{tabular}{|c|c|c|c|c|c|c|c|c|c|c|c|}
\hline $\mathrm{MO}$ & $\mathrm{Si}^{(1)}$ & $\mathrm{Si}^{(2)}$ & $\mathrm{P}^{(3)}$ & $\mathrm{P}^{(4)}$ & $\mathrm{Al}^{3+}$ & $\mathrm{Ca}^{2+}$ & $\mathrm{Mg}^{2+}$ & $\mathrm{K}$ & SB & $\mathrm{H}+\mathrm{Al}$ & $\mathrm{V}$ \\
\hline $\mathrm{g} \mathrm{kg}^{-1}$ & 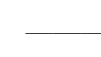 & $\mathrm{m}$ & $m^{-3}$ & 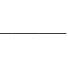 & 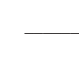 & 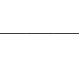 & $\mathrm{mm}$ & $\mathrm{m}^{-3}$ & & - & $\%$ \\
\hline 20,3 & 14,01 & 108,02 & 1,0 & 11 & 20,3 & 6,7 & 2,0 & 0,9 & 11,6 & 111 & 9 \\
\hline
\end{tabular}

(1) $\mathrm{CaCl}_{2} 0,01 \mathrm{~mol} \mathrm{~L}^{-1}$; (2) ácido acético $0,05 \mathrm{~mol} \mathrm{~L}^{-1} ;{ }^{(3)}$ Mehlich; ${ }^{(4)}$ remanescente. 
Tabela 2. Caracterização textural do Latossolo Vermelho distroférrico utilizado no experimento (Dourados, MS, 2007).

\begin{tabular}{ccccc}
\hline \multirow{2}{*}{$\begin{array}{c}\text { Profundidade } \\
(\mathrm{cm})\end{array}$} & \multicolumn{4}{c}{ Granulometria $\left(\mathrm{g} \mathrm{kg}^{-1}\right)$} \\
\cline { 2 - 5 } & Areia grossa & Areia fina & Silte & Argila \\
\hline $0-20$ & 89,0 & 60,0 & 91,0 & 760,0 \\
\hline
\end{tabular}

em período de incubação de 20 dias, para eliminar o $\mathrm{pH}$, como fator de interferência no estudo.

Ao final deste segundo período de incubação, as amostras foram secas ao ar, peneiradas em peneira com malhas de $2 \mathrm{~mm}$ de abertura e homogeneizadas. Subamostras de $3,5 \mathrm{dm}^{-3}$ de solo receberam tratamentos com as cinco doses de P, juntamente com a adubação básica, que constou da aplicação de $40 \mathrm{mg} \mathrm{dm}^{-3}$ de sulfato de potássio e de formulado de micronutrientes contendo $\mathrm{B}, \mathrm{Cu}, \mathrm{Fe}, \mathrm{Mo}, \mathrm{Mn}$ e $\mathrm{Zn}$.

Em cada vaso, foram semeadas seis sementes de milho (Zea mays L.), variedade BR-206 (híbrido duplo, ciclo precoce). No desbaste, realizado duas semanas após a semeadura, foi deixada uma planta por vaso. Aos 10, 20 e 30 dias após a semeadura, foram realizadas adubações de cobertura com ureia, na dose de $25 \mathrm{mg} \mathrm{dm}^{-3}$ de $\mathrm{N}$ cada. A irrigação dos vasos com água destilada, durante o período experimental, foi realizada de modo a manter o teor de água em $60 \%$ do volume total de poros do solo, cuja reposição das perdas foi controlada por meio de pesagem dos vasos.

Após 45 dias da semeadura, procedeu-se à colheita das plantas que se encontravam no estádio fenológico V4. Estas foram cortadas rente ao solo, lavadas em água corrente e destilada e secas em estufa de circulação forçada de ar, a $65^{\circ} \mathrm{C}$, até atingir peso constante. $\mathrm{O}$ material foi triturado em moinho tipo Willey e submetido a análises químicas de Si e P. A metodologia empregada para as análises de Si nas folhas foi a descrita em Korndörfer et al. (2004) e o P foi determinado segundo Malavolta et al. (1997).

Subamostras de terra foram retiradas de cada vaso, para análise de $\mathrm{P}$ e Si. Para isto, procedeu-se à secagem ao ar, destorroamento, peneiramento em peneira com malhas de $2 \mathrm{~mm}$ de abertura e homogeneização da terra dos vasos. Os teores de Si no solo foram extraídos com a utilização de soluções de cloreto de cálcio a $0,01 \mathrm{~mol} \mathrm{~L}^{-1}$ e ácido acético a $0,5 \mathrm{~mol} \mathrm{~L}^{-1}$ e os teores de P pelos métodos Olsen e Mehlich 1.

Os dados obtidos foram submetidos a análise de variância e as equações de regressão ajustadas em função das doses de $\mathrm{P}$, utilizando-se o teste $\mathrm{t}$, a $5 \%$, com o auxílio do aplicativo computacional Sistema de Análises Estatísticas e Genéticas (SAEG), segundo Ribeiro Júnior (2001).

\section{RESULTADOS E DISCUSSÃO}

\section{Silício no solo}

Os teores de Si no solo, determinados usando-se os extratores cloreto de cálcio a $0,01 \mathrm{~mol} \mathrm{~L}^{-1}$ ou ácido acético a $0,05 \mathrm{~mol} \mathrm{~L}^{-1}$, aumentaram, em função da aplicação da escória (Tabela 3). Resultados semelhantes foram observados por Melo et al. (2003) e Camargo et al. (2007). Os menores teores de Si encontrados nos tratamentos que não receberam adubação silicatada, para ambos os extratores utilizados, são consequência do seu avançado grau de intemperismo e lixiviação, assim como dos elevados teores de óxidos de $\mathrm{Fe}$ e $\mathrm{Al}$, que são os principais responsáveis pela adsorção do Si da solução do solo (Tokura et al. 2007).

Para todas as doses de $\mathrm{P}$ adicionadas, os valores de Si solúvel obtidos pelos extratores cloreto de

Tabela 3. Teores de Si no solo solúvel, nos extratores cloreto de cálcio e ácido acético, em função de doses de P adicionado (Dourados, MS, 2007).

\begin{tabular}{|c|c|c|c|c|c|}
\hline \multirow{2}{*}{ Escória } & \multicolumn{5}{|c|}{$\mathrm{P}$ adicionado $\left(\mathrm{mg} \mathrm{dm}^{-3}\right)$} \\
\hline & 0 & 96 & 192 & 288 & 480 \\
\hline \multicolumn{6}{|c|}{ Si solúvel em cloreto de cálcio $\left(\mathrm{mg} \mathrm{dm^{-3 } )}\right.$} \\
\hline Sem escória & $14,09 \mathrm{~b}$ & $14,48 \mathrm{~b}$ & $14,89 \mathrm{~b}$ & $23,54 \mathrm{~b}$ & $16,55 \mathrm{~b}$ \\
\hline Com escória & $24,13 \mathrm{a}$ & $24,92 \mathrm{a}$ & $35,96 \mathrm{a}$ & $40,92 \mathrm{a}$ & $29,25 \mathrm{a}$ \\
\hline \multicolumn{6}{|c|}{ Si solúvel em ácido acético $\left(\mathrm{mg} \mathrm{dm^{-3 } )}\right.$} \\
\hline Sem escória & $108,42 \mathrm{~b}$ & $120,74 \mathrm{~b}$ & $122,59 \mathrm{~b}$ & $132,27 \mathrm{~b}$ & $131,48 \mathrm{~b}$ \\
\hline Com escória & $136,42 \mathrm{a}$ & $147,87 \mathrm{a}$ & $148,18 \mathrm{a}$ & $149,26 \mathrm{a}$ & $142,99 \mathrm{a}$ \\
\hline
\end{tabular}

Médias seguidas da mesma letra, na coluna, diferem, significativamente, a $5 \%$, pelo teste Tukey. 
cálcio e ácido acético foram superiores, quando da aplicação da escória de siderurgia (Tabela 3). Estes resultados concordam com os obtidos por Lopes (1977), Oliveira (1984), Leite (1997) e Carvalho (1999), os quais evidenciaram que, nos tratamentos com aplicação de $\mathrm{P}$, foram obtidos maiores teores de Si solúvel, quando comparados aos tratamentos sem sua aplicação. Este fato pode ser explicado pelo princípio de sorção recíproca, segundo o qual quanto maior a concentração de $\mathrm{P}$, menor a quantidade de Si capaz de ser retida pela fase sólida do solo, visto que o $\mathrm{P}$ ocupa os mesmos sítios de adsorção que o $\mathrm{Si}$ e tem maior afinidade com o colóide, podendo deslocar, facilmente, o Si adsorvido (Camargo et al. 2005, Carneiro et al. 2006).

Os resultados encontrados neste trabalho evidenciam, no entanto, que o efeito do Si no aumento da disponibilidade de $\mathrm{P}$ e vice-versa está mais relacionado ao aumento do $\mathrm{pH}$ do que à dessorção de $\mathrm{P}$. Resultados semelhantes foram encontrados por Ma \& Takahashi (1990 e 1991), utilizando plantas de arroz.

Os teores máximos de Si no solo (Figura 1), solúveis em cloreto de cálcio, variaram de $21,84 \mathrm{mg} \mathrm{dm}^{-3}$ (sem escória) a 37,22 $\mathrm{mg} \mathrm{dm}^{-3}$ (com escória), respectivamente, com as doses de $\mathrm{P}$ de $282,25 \mathrm{mg} \mathrm{dm}^{-3} \mathrm{e}$ $306,00 \mathrm{mg} \mathrm{dm}^{-3}$.

Os teores máximos de Si no solo, solúveis em ácido acético (Figura 2), variaram de 141,28 $\mathrm{mg} \mathrm{dm}^{-3}$ (sem escória) a 148,45 $\mathrm{mg} \mathrm{dm}^{-3}$ (com escória), respectivamente, com as doses de $\mathrm{P}$ de $480 \mathrm{mg} \mathrm{dm}^{-3} \mathrm{e}$ $231,5 \mathrm{mg} \mathrm{dm}^{-3}$. Na ausência da adubação fosfatada, foram constatados os menores valores de Si solúvel em ácido acético $\left(108,88 \mathrm{mg} \mathrm{dm}^{-3}\right.$, na ausência de

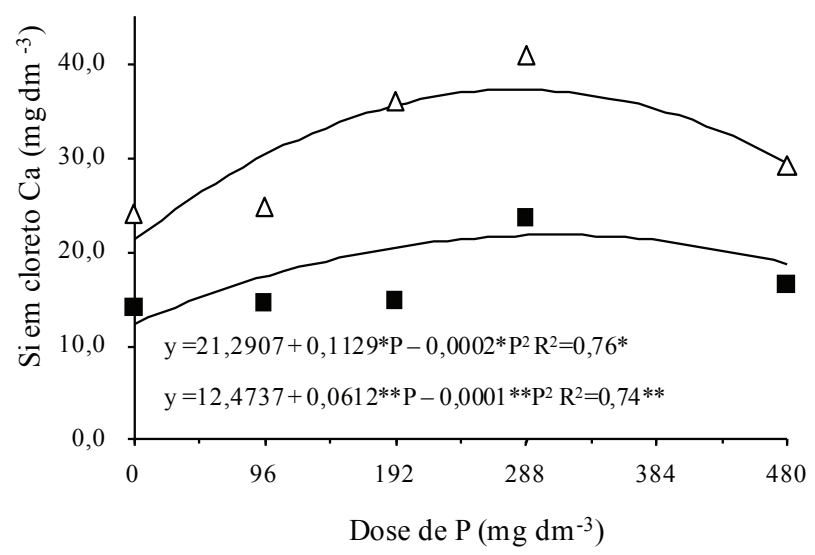

Figura 1. Si solúvel em solução de cloreto de cálcio, em função de doses de P, sem (ロ) e com $(\Delta)$ aplicação de escória ao solo. ** e *: Significativos a $1 \%$ e $5 \%$, respectivamente, pelo teste $\mathrm{t}$ (Dourados, MS, 2007).

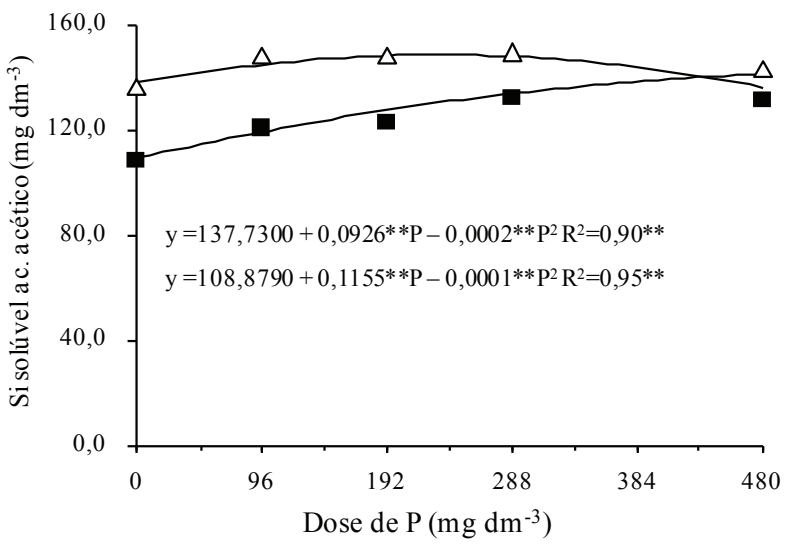

Figura 2. Si solúvel em solução de ácido acético, em função de doses de $\mathrm{P}, \operatorname{sem}(\boldsymbol{\square})$ e com $(\Delta)$ aplicação de escória ao solo. ** Significativo a $1 \%$, pelo teste t (Dourados, MS, 2007).

aplicação de escória, e 137,73 $\mathrm{mg} \mathrm{dm}^{-3}$, na presença de escória), onde a presença de escória, com o fornecimento de $300 \mathrm{mg} \mathrm{dm}^{-3}$ de Si total, elevou, em $26,5 \%$, os teores de Si extraído por este extrator, o que representa uma taxa de recuperação de $9,6 \%$ do Si total aplicado.

Para o extrator ácido acético, são considerados baixos teores aqueles menores que $6 \mathrm{mg} \mathrm{dm}^{-3}$, médios os entre $6 \mathrm{mg} \mathrm{dm}^{-3}$ e $24 \mathrm{mg} \mathrm{dm}^{-3} \mathrm{e}$ altos os teores acima de $24 \mathrm{mg} \mathrm{dm}^{-3}$ (Reis et al. 2008). Vale destacar que os teores iniciais de Si extraídos pelo ácido acético, no solo do presente estudo, estão bem acima do que Korndörfer et al. (1999b) consideram como adequados (>10 $\mathrm{mg} \mathrm{dm}^{-3} \mathrm{de} \mathrm{Si}$ ) para a obtenção de produtividades máximas na cultura do arroz, com chances de respostas à aplicação deste elemento para teores menores do que o mencionado.

Pereira et al. (2007) também encontraram teores menores de Si extraídos em cloreto de cálcio, quando comparados ao ácido acético, porém, este último foi o que apresentou menor correlação entre o teor de Si na planta e no solo $\left(\mathrm{R}^{2}=0,81\right.$, para cloreto de cálcio, e $\mathrm{R}^{2}=0,20 \%$, para o ácido acético). Resultados semelhantes foram encontrados por Camargo et al. (2007), trabalhando com Latossolo Vermelho álico de textura argilosa, e Paim et al. (2009), utilizando Latossolo Vermelho distroférrico. Estes dados diferem daqueles encontrados por Ramos et al. (2008), que trabalharam com amostras de Neossolo quartzarênico órtico típico, onde o extrator ácido acético apresentou coeficiente de determinação superior $\left(\mathrm{R}^{2}=0,87\right)$ ao do cloreto de cálcio $\left(\mathrm{R}^{2}=0,76\right)$, na 
determinação dos teores de $\mathrm{Si}$ disponível. O extrator cloreto de cálcio tem a propriedade de simular a força iônica da solução e o pH do solo, entretanto, pouco tem sido feito para entender a cinética de liberação dos cátions da fase sólida para a solução (Korndörfer et al. 1999a).

Como mencionado anteriormente, o $\mathrm{P}$ pode ocupar as superfícies adsorvedoras com menor atração para o Si, ocorrendo sua liberação para a solução do solo. A interferência de P no método de determinação de Si solúvel tem sido eliminada com a adição de ácidos orgânicos, como o ácido tartárico usado no experimento, além de ácido cítrico e oxálico. O P e o Si formam compostos análogos, fosfomolibdato e silicomolibdato, que são lidos no mesmo comprimento de onda e, se não fosse retirada esta influência, os teores de Si resultantes seriam superestimados (Camargo et al. 2005). Nota-se que aplicação de escória, na ausência de adubação fosfatada, elevou em $70,7 \%$ o teor de Si solúvel em cloreto de cálcio, em relação ao tratamento sem aplicação da escória. Contudo, tal elevação representa apenas $2,94 \%$ dos $300 \mathrm{mg} \mathrm{dm}^{-3}$ de Si aplicados na forma de escória de siderurgia.

Os extratores tendem a atuar no $\mathrm{Si}$ em diferentes componentes da matriz do solo. Soluções diluídas salinas, como o $\mathrm{CaCl}_{2}$, mensuram a quantidade de $\mathrm{Si}$ disponível em solução do solo, enquanto resultados obtidos com uso de ácido acético indicam que o $\mathrm{Si}$ solubilizado origina-se de polímeros simples. O extrator ácido acético pode não ser adequado, quando se aplica ao solo uma fonte rica em $\mathrm{Si}$, mas de baixa eficiência. O ácido acético é capaz de solubilizar Si da fonte utilizada e não disponível às plantas, tal como formas polimerizadas (ácido polisilícico), as quais não são solúveis em cloreto de cálcio. Isto pode ser devido ao $\mathrm{pH}$ do ácido acético ser muito baixo $(1,0$ a 2,0) para a formação do complexo silico-molibdico (Korndörfer et al. 1999b). Resultados semelhantes foram obtidos por Berthelsen et al. (2002) e Sumida (2002), que mostraram a eficiência das soluções ácidas, quando comparadas a soluções de $\mathrm{pH}$ neutro. Este fenômeno é análogo ao que ocorre com o P, quando se aplica fosfato natural e são feitas análises utilizando-se o duplo ácido (Mehlich-1) como extrator. A disponibilidade do nutriente no solo fica superestimada (Pereira et al. 2003).

O ácido acético também superestima o teor de Si nos solos que receberam aplicação de fontes ricas em aluminossilicatos, como as escórias de alto- -forno. O Si ligado ao Al é mais solúvel em meio ácido, fazendo com que estas fontes liberem mais este elemento, quando se utiliza um extrator ácido (Pereira et al. 2007).

\section{Silício na planta}

A aplicação de escória de siderurgia influenciou, significativamente, o conteúdo de Si na matéria seca da parte aérea do milho, o que não ocorreu para o conteúdo de $\mathrm{P}$ (Tabela 4) e para a interação Si x P.

O conteúdo de Si na parte aérea do milho, superior ao observado sem a aplicação de escória, evidencia a solubilização da mesma, com elevação de Si na solução do solo e o consequente acúmulo deste elemento no tecido vegetal. Este aumento também foi observado por Barbosa et al. (2008), porém, este fato não ocorreu com o conteúdo de $\mathrm{P}$, provavelmente devido a alguma reação de constituintes da escória ( $\mathrm{Ca}$, por exemplo), que, por meio de precipitação deste cátion com o $\mathrm{P}$ da solução do solo, reduz a absorção de P. Ao contrário do verificado no presente estudo, Cessa (2005) constatou que a aplicação de $300 \mathrm{mg} \mathrm{dm}^{-3}$ de $\mathrm{Si}$, na forma de metassilicato de sódio pentahidratado, promoveu aumento significativo nos conteúdos de $\mathrm{P}$, na parte aérea do sorgo, em todas as doses de $\mathrm{P}$ aplicadas, em amostras de Latossolo Vermelho distroférrico de textura muito argilosa.

A aplicação de P influenciou, significativamente, os conteúdos de Si e P na matéria seca da parte aérea do milho (Figuras 3 e 4). Os conteúdos de $\mathrm{Si}$ na matéria seca da parte aérea do milho (Figura 3) variaram de 9,93 $\mathrm{g} \mathrm{kg}^{-1}$ a 14,21 $\mathrm{g} \mathrm{kg}^{-1}$, sem e com a dose de $480 \mathrm{mg} \mathrm{dm}^{-3}$ de P, respectivamente. Epstein (1999), em extensa revisão sobre elementos minerais, comenta que, na literatura, são encontrados teores de Si na matéria seca da parte aérea que variam de

Tabela 4. Conteúdos de silício e fósforo na matéria seca da parte aérea do milho, em função de doses de escória agrícola, no conjunto das doses de P (Dourados, MS, 2007).

\begin{tabular}{ccc}
\hline \multirow{2}{*}{ Escória } & \multicolumn{2}{c}{ Conteúdos na matéria seca da parte aérea } \\
& $\mathrm{Si}$ & $\mathrm{P}$ \\
\cline { 2 - 3 }$\left(\mathrm{mg} \mathrm{dm}^{-3}\right)$ & \\
\hline Sem escória & $10,43 \mathrm{a}$ & $9,43 \mathrm{a}$ \\
Com escória & $13,18 \mathrm{~b}$ & $8,45 \mathrm{a}$ \\
\hline
\end{tabular}

Médias seguidas da mesma letra, na coluna, não diferem, significativamente, a $5 \%$, pelo teste Tukey. 


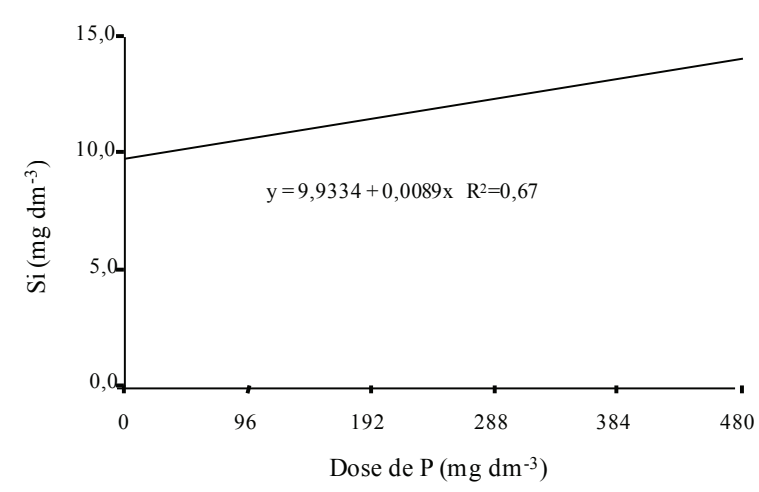

Figura 3. Conteúdo de silício na matéria seca da parte aérea do milho, em função de doses de fósforo (Dourados, MS, 2007).

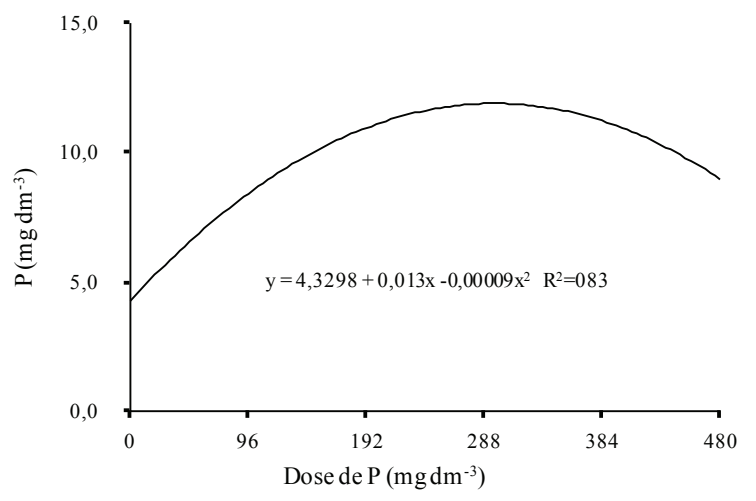

Figura 4. Conteúdo de fósforo na matéria seca da parte aérea do milho, em função de doses de fósforo, no conjunto das doses de silicato (Dourados, MS, 2007).

0,1\% a $10 \%\left(1 \mathrm{~g} \mathrm{~kg}^{-1}\right.$ a $\left.100 \mathrm{~g} \mathrm{~kg}^{-1}\right)$, sendo, também, encontrados, ainda que raramente, valores inferiores ou superiores a estes.

$\mathrm{O}$ conteúdo máximo de $\mathrm{P}\left(11,64 \mathrm{~g} \mathrm{~kg}^{-1}\right)$ na matéria seca da parte aérea do milho (Figura 4) foi obtido com a dose de $285,0 \mathrm{mg} \mathrm{dm}^{-3}$. Os resultados de conteúdos de Si e P se assemelham aos observados por Leite (1997) e Cessa (2005), em seus trabalhos sobre a interação Si x P, em Latossolos da mesma classe do presente estudo, os quais também constataram aumentos nos conteúdos de Si e de $\mathrm{P}$ na parte aérea do sorgo, em função de doses de P. Vale destacar a ocorrência de aumentos lineares para o conteúdo de $\mathrm{Si}$, neste e nos dois trabalhos acima mencionados, em função de doses de $\mathrm{P}$, o que sugere a ação do $\mathrm{P}$, adicionado como fertilizante, no deslocamento de $\mathrm{Si}$ de sítios de adsorção na fase sólida para a solução do solo e, consequentemente, maior absorção pelas plantas.

\section{CONCLUSÕES}

1. A solução de ácido acético extraiu mais Si do que a solução de cloreto de cálcio, independentemente da fertilização com escória. A fertilização fosfatada elevou a disponibilidade de $\mathrm{Si}$, avaliada por estes extratores, com maiores teores observados quando da aplicação da escória.

2. No Brasil, onde os solos são altamente dependentes da correção de acidez, o ácido acético não deveria ser utilizado, por poder superestimar os teores de Si que não correspondem àqueles disponíveis para as plantas.

3. A fertilização fosfatada, além de elevar os conteúdos de P na parte aérea do milho, também o fez, de modo bem menos expressivo, para os conteúdos de $\mathrm{Si}$, independentemente da aplicação ou não do silicato.

\section{REFERÊNCIAS}

ALVAREZ, V. et al. Determinação e uso do fósforo remanescente. Boletim da Sociedade Brasileira de Ciência do Solo, Viçosa, v. 25, n. 1, p. 27-32, 2000.

BARBOSA, N. C. et al. Formas de aplicação de silicato de cálcio e magnésio na cultura do sorgo em Neossolo quartzarênico de Cerrado. Pesquisa Agropecuária Tropical, Goiânia, v. 38, n. 4, p. 290-296, 2008.

BERTHELSEN, S. et al. Effect of Ca-silicate amendments on soil chemical properties under a sugarcane cropping system. In: SILICON INAGRICULTURECONFERENCE, 2., 2002, Tsuruoka. Anais... Tsuruoka: Japanese Society of Soil Science and Plant Nutrition, 2002. p. 57.

CAMARGO, M. S. et al. Extratores de silício solúvel em solos: influência do calcário e fósforo. Bioscience Journal, Uberlândia, v. 21, n. 2 , p. 9-19, 2005.

CAMARGO, M. S. et al. Soil reaction and absorption of silicon by rice. Scientia Agricola, Piracicaba, v. 64, n. 2, p. 176-180, 2007.

CARNEIRO, C. E. A. et al. Calcário, potássio, fosfato e silício na produtividade do solo. Acta Scientiarum Agronomy, Maringá, v. 28, n. 4, p. 465-470, 2006.

CARVALHO, R. Interações silício-fósforo em Latossolo Vermelho-Escuro e Cambissolo cultivados com mudas de eucalipto. 1999. 89 f. Tese (Doutorado em Solos e Nutrição de Plantas)-Universidade Federal de Lavras, Lavras, 1999.

CASAGRANDE, J. C. et al. Adsorção de fosfato e sulfato em solos com cargas elétricas variáveis. Revista Brasileira de Ciência do Solo, Viçosa, v. 27, n. 1, p. 51-59, 2003. 
CESSA, R. M. A. Absorção de fósforo e crescimento do sorgo em função da pré-aplicação de silício em um Latossolo Vermelho distroférrico. 2005. 55 f. Dissertação (Mestrado em Agronomia)-Universidade Federal do Mato Grosso do Sul, Dourados, 2005.

EPSTEIN, E. Silicon. Annual Review of Plant Physiology and Plant Molecular Biology, Palo Alto, v. 50, n. 1, p. 641664, 1999.

KORNDÖRFER, G. H. et al. Avaliação de métodos de extração de silício para solos cultivados com arroz de sequeiro. Revista Brasileira de Ciência do Solo, Viçosa, v. 23, n. 2, p. 101-106, 1999a.

KORNDÖRFER, G. H. et al. Efeito da aplicação de silicato de cálcio em solos cultivados com arroz de sequeiro. Revista Brasileira de Ciência do Solo, Viçosa, v. 23, n. 3, p. 623-629, 1999b.

KORNDÖRFER, G. H.; PEREIRA, H. S.; CAMARGO, M. S. Análise de silício: solo, planta e fertilizantes. Uberlândia; GPSi/ICIAG/UFU, 2004.

LEITE, P. da C. Interação silício-fósforo em Latossolo Roxo cultivado com sorgo em casa-de-vegetação. 1997. 86 f. Tese (Doutorado em Solos e Nutrição de Plantas)Universidade Federal de Viçosa, Viçosa, 1997.

LIMA FILHO, O. F.; LIMA, M. T. G.; TSAI, S. M. O silício na agricultura. Informações Agronômicas, Piracicaba, v. 87, n. 1, p. 1-7, 1999.

LOPES, M. S. Relações entre pH e adsorção de P e Si em solos. 1977. 117 f. Tese (Doutorado em solos e Nutrição de Plantas)-Universidade Federal do Rio Grande do Sul, Porto Alegre, 1977.

MA, J. F.; TAKAHASHI, E. Effect of silicon on growth and phosphorus uptake of rice. Plant and Soil, Hague, v. 126 , n. 2, p. 115-119, 1990.

MA, J. F.; TAKAHASHI, E. Effect of silicate on phosphate availability for rice in a P-deficient soil. Plant and Soil, Hague, v. 133, n. 2, p. 151-155, 1991.

MA, J. F.; MIYAKE, Y.; TAKAHASHI, E. Silicon as a beneficial element for crop plant. In: DATNOFF, L. E.; SNYDER, G. H.; KORNDÖRFER, G. H. (Eds.). Silicon in agriculture. Amsterdam: Elsevier Science, 2001. p. 17-39.

MALAVOLTA, E.; VITTI, G. C.; OLIVEIRA, S. A. de. Avaliação do estado nutricional das plantas: princípios e aplicações. 2. ed. Piracicaba: Potafos, 1997.

MELO, S. P. et al. Silicon accumulation and water deficit tolerance in Brachiaria grasses. Scientia Agricola, Piracicaba, v. 60, n. 4, p. 755-759, 2003.

NOVAIS, R. F.; SMYTH, T. J. Fósforo em solo e planta em condições tropicais. Viçosa: UFV, 1999.
OLIVEIRA, M. G. A. Determinação, adsorção e deslocamento recíproco de silício e fósforo em Latossolos do Triângulo Mineiro. 1984. 88 f. Dissertação (Mestrado em Solos e Nutrição de Plantas)-Universidade Federal de Viçosa, Viçosa, 1984.

OTSUBO, A. A.; COUTINHO, L. M. Saturação por bases, cálcio e magnésio na produção de massa seca de alfafa (Medicago sativa L.). Revista Cerrados, Brasília, DF, v. 2, n. 1, p. 51-54, 2001.

PAIM, L. R. et al. Correlação de silício e fósforo em sorgo fertilizado com escória de siderurgia e fosfato. In: CONGRESSO DE PÓS-GRADUAÇÃO DA UFLA, 18., 2009, Lavras. Anais... Lavras: UFLa, 2009. 1 CD-ROM.

PEREIRA, H. S. et al. Avaliação de fontes e extratores de silício no solo. Pesquisa Agropecuária Brasileira, Brasília, DF, v. 42, n. 2, p. 239-247, 2007.

PEREIRA, H. S. et al. Extratores de silício disponível em escórias e fertilizantes. Revista Brasileira de Ciência do Solo, Viçosa, v. 27, n. 2, p. 265-274, 2003.

RAMOS, L. A.; KORNDÖRFER, G. H.; NOLLA, A. Acúmulo de silício em plantas de arroz do ecossistema de várzea submetido à aplicação de diferentes fontes. Bragantia, Campinas, v. 67, n. 3, p. 751-757, 2008.

REIS, M. A. et al. Aplicação de silício em arroz de terras altas irrigado por aspersão. Acta Scientiarum Agronomy, Maringá, v. 30, n. 1, p. 37-43, 2008.

RIBEIRO JÚNIOR, J. I. Análises estatísticas no SAEG. Viçosa: UFV, 2001.

SNYDER, G. H. Methods for silicon analysis in plants, soils and fertilizers. In: DATNOFF, L. E.; SNYDER, G. H.; KORNDÖRFER, G. H. Silicon in agriculture. Amsterdam: Elsevier, 2001. p. 185-196.

SOUZA, D. M. G. de; LOBATO, E.; REIN, T. A. Adubação com fósforo. In: SOUZA, D. M. G. de; LOBATO, E. (Eds.). Cerrado: correção do solo e adubação. Planaltina: Embrapa Cerrados, 2002. p. 147-167.

SUMIDA, H. Plant available silicon in paddy soils. In: SILICON IN AGRICULTURE CONFERENCE, 2., 2002, Tsuruoka. Anais... Tsuruoka: Japanese Society of Soil Science and Plant Nutrition, 2002. p. 43-49.

TEDESCO, M. J.; VOLKWEISS, S. J.; BOHNEN, H. Análises de solo, plantas e outros materiais. Porto Alegre: UFRGS, 1985.

TISDALE, S. et al. Soil fertility and fertilizers: an introduction to nutrient management. New York: Prentice Hall, 1985.

TOKURA, A. M. et al. Silício e fósforo em diferentes solos cultivados com arroz de sequeiro, Acta Scientiarum Agronomy, Maringá, v. 29, n. 1, p. 9-16, 2007. 